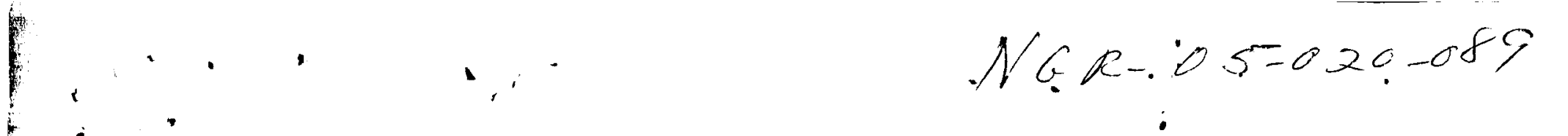

\title{
ION DISTRIBUTION AND TEMPERATURE
}

IN THE TOPSIDE IONOSPHERE

OBTAINED FROM THE ALOUETTE SATELIITE

\section{by}

Theodore M. Watt

Radioscience Laboratory

stanford University

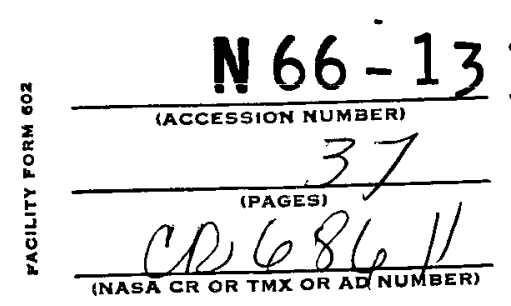

GPO PRICE $\mathbf{\$}$
CFSTI PRICE(S) $\mathbf{\$}$

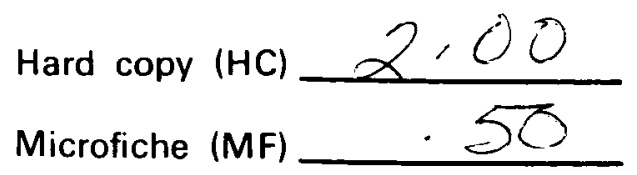

ff 653 July 65 



\section{INTRODUCTION}

It is believed that the most abundant ions in the upper ionosphere are $\mathrm{O}^{+}, \mathrm{H}_{e}^{+}$, and $\mathrm{H}^{+}$. There is little doubt that $\mathrm{O}^{+}$is the dominant ion at least between $200 \mathrm{~km}$ and $500 \mathrm{~km}$ (Johnson, et al., 1958, Taylor, et al., 1963). At altitudes above about $1500 \mathrm{~km}$ it is generally believed that $\mathrm{H}^{+}$is the dominant ion. Recent measurements of hybrid resonances at $1,000 \mathrm{~km}$ by Barrington, et al, (1964) suggest comparable ratios of $\mathrm{H}^{+}$to $\mathrm{O}^{+}$at this altitude. On the other hand, the relative abundance of $\mathrm{H}_{e}^{+}$in the ionosphere is not yet fully established. Nicolet (1961) suggested that neutral helium might be an important constituent of the upper atmosphere. King, et al (1964) present topside sounder data recorded at singapore in october 1962 suggesting a nighttime $\mathrm{O}^{+}-$to $-\mathrm{H}_{e}^{+}$transition at about $600 \mathrm{~km}$. Bowen et al (1964) show midlatitude results obtained during the summer of 1962 from the Ariel satellite, indicating that, at night, $\mathrm{H}_{e}^{+}$is a dominant ion at $800 \mathrm{~km}$, with $\mathrm{O}^{+}$and $\mathrm{H}^{+}$also present in significant quantities.

In this paper we consider a detailed analysis of topside electron density profiles. Since the electron density distribution in the topside ionosphere varies as a function both of relative ion concentration and the electron and ion temperature, such an analysis provides information about charged particle temperatures as well as distributions.

The relationship between electron density, electron and ion temperature and relative ion concentration can perhaps best be described in terms of the parameter "plasma scale height." In this paper we wish to define plasma scale height as the negative reciprocal of the normalized height gradient of electron density. symbolically, this is

$$
H=-\frac{n_{e}}{\partial n_{e} / \partial h}
$$


where $A$ is plasma scale height and $n_{e}$ is electron density. Integration of Eq. (1) yields

$$
n_{e}(z)=n_{0} \exp \left[-\int_{0}^{z} \frac{d h}{A}\right]
$$

which, for the special case $\sharp$ = constant, reduces to

$$
n_{e}(z)=n_{0} \exp \left[-\frac{z}{\not y}\right]
$$

where $z$ and $h$ are both height variables and $n_{0}$ is electron density at a reference height defined by $h=0$.

We will show that, for a statistically neutral mixture of particles in diffusive equilibrium, plasma scale height is given by

$$
\forall=\frac{T_{e}+T_{i}}{T_{e}^{\prime}+T_{i}^{\prime}+\left\langle m_{i}>g / k\right.}
$$

where $T_{e}$ and $T_{i}$ are electron and ion temperatures respectively, primes indicate derivatives with respect to height, $\left\langle\mathrm{m}_{i}\right\rangle$ is the mean mass of all ions present, $g$ is the acceleration of gravity and $k$ is Boltzmann's constant. Thus, using plasma scale height profiles obtained from Alouette topside soundings, information can be obtained about electron temperature, ion temperature and relative ion concentration in the topside ionosphere.

It can be seen that for the case in which no height gradients of temperature are present, Eq. (4) reduces to a form which appears to be in very common usage today. As is apparent by inspection of Eq. (4), however, if significant height gradients of temperature exist, their omission will lead to serious errors in deduced values for electron and ion temperature. 
Since December 4, 1962, signals from the Alouette have been monitored on a routine basis by the satellite receiving station at the Radioscience Laboratory of Stanford University. Details of the acquisition of the telemetered data by the recording station are described in Thomas and sader (1964). The reduction of these data to electron density [N(h)] profiles is described by Thomas, et al $(1965 \mathrm{a}, \mathrm{b})$.

The reduction of ionograms has been performed through a joint effort of the space Sciences Division of Ames Research Center and Stanford Research Institute. The format of each profile was that of a tabulation of values of electron density at heights of $1000 \mathrm{~km}, 950 \mathrm{~km}, 900 \mathrm{~km}$, etc., down to the level of maximum electron density, below which no data were obtained. As part of the same computer program, a corresponding tabulation of scale height values at the same true heights was easily obtained in accordance with the definition of Eq. (1). Published tables of these data are now in press (Thomas, Rycroft and Colin, 1965).

Data were obtained for the periods May-July 1963 and November 1963 - January 1964 and these groups are called "summer" and "winter" respectively. During each three-month period a compiete diurn=l onortrum of data was obtained. Data obtained for local mean satellite times (LMT) between 2300 ana u4uv were considered "nightime" data; data for the period 0800 IMT to 1700 LMT were classified as "daytime" data. We will derive Eq. (4) and the corresponding expressions for the distributions of number densities, after which we will examine the data in detail.

II. THEORY

We are here considering the theoretical distribution of ions and electrons in the region bounded by heights of $400 \mathrm{~km}$ and 900 $\mathrm{km}$, and dip latitudes of $48^{\circ}$ and $78^{\circ}$ North. 
The following simplifying assumptions are appropriate:

1. The ionosphere consists entirely of neutral particles and a statistically neutral mixture of electrons and singly charged ions of oxygen $\left(\mathrm{O}^{+}\right)$, helium $\left(\mathrm{H}_{\mathrm{e}}^{+}\right)$, and hydrogen $\left(\mathrm{H}^{+}\right)$.

2. The medium is in a state of diffusive equilibrium, thus diffusion is the dominant process controlling the distribution of electrons and ions, and we can neglect the effect of production, loss, and time derivatives of all quantities.

3. The ionosphere is horizontally stratified, i.e. horizontal gradients of all quantities are much smaller than vertical gradients.

4. There is no net transport velocity associated with any species.

5. In any small region of space, all ions are in thermal equilibrium among themselves.

For conditions such as these, in which there is no production or loss, the equilibrium distribution of any species can be obtained by forming a balance of all forces present. For this case the appropriate force equation for each species is obtained by balancing the pressure gradient against all other forces, as:

$$
\nabla p=n q \bar{E}+\overline{\bar{F}}
$$

where

$$
\mathrm{p}=\mathrm{nkT}
$$

Here $\mathbf{p}$ is the partial pressure of any species of particle, $T$ is particle temperature, $\bar{E}$ is any electric field present, and $\bar{F}$ accounts for all non-coulomb forces present. In the case of a rotating earth, $\overline{\mathrm{F}}$ is the sum of gravitational and centrifugal forces, but for altitudes less than $1000 \mathrm{~km}$, it can be easily shown that the centrifugal force is negligible, and Eq. (5) may be expressed as 


$$
\frac{d p}{d h}=n q \bar{E}-n m g
$$

where $h$ is a coordinate in the radial direction. Combining Eqs. (6) and (7), we have:

$$
\frac{d}{d h}\left(n_{e} k T_{e}\right)=-n_{e} m_{e} g-n_{e}|q| E
$$

for electrons, and:

$$
\frac{d}{d h}\left(n_{i} k T_{i}\right)=-n_{i} m_{i} g+n_{i}|q| E
$$

for each ion species.

Performing the differentiation on (8) and (9), we have:

$$
\begin{aligned}
& k T_{e} \frac{d n_{e}}{d h}+k n_{e} \frac{d T_{e}}{d h}=-n_{e} m_{e} g-n_{e}|q| E \\
& k T_{i} \frac{d n_{i}}{d h}+k n_{i} \frac{d T_{i}}{d h}=-n_{i} m_{i} g+n_{i}|q| E
\end{aligned}
$$

Summing (11) over all ions, we have

$$
k T_{i} \frac{d}{d h} \Sigma n_{i}+k \frac{d T_{i}}{d h} \sum_{i} n_{i}=-\sum_{i} n_{i} m_{i} g+\sum_{i} n_{i}|q| E
$$

since, by assumption (5), all ions have the same temperature. Noting that $n_{e}=\sum_{i} n_{i}, m_{i} \gg m_{e}$ for any ion, and defining mean ionic mass as

$$
<m_{i}>=\frac{\sum_{1} n_{i} m_{i}}{n_{e}}
$$


we can add Eqs. (10) and (12) and obtain

$$
k\left(T_{e}+T_{i}\right) \frac{d n_{e}}{d h}+k n_{e} \frac{d}{d h}\left(T_{e}+T_{i}\right)=-n_{e}<m_{i}>g
$$

Solving for $-\mathrm{n}_{e} / \mathrm{n}_{e}{ }^{\prime}$, we easily obtain Eq. (4). Integrating Eq. (9) from $h=0$ to $h=z$, we obtain

$$
n_{i}(z)=\frac{n_{i o} T_{i o}}{T_{i}(z)} \exp \left[\int_{0}^{z} \frac{|q| E-m_{i} g}{k T_{i}} d h\right]
$$

From Eq. (14) we can express the fractional proportion of any constituent as;

$$
p_{i}=\frac{n_{i}}{\sum_{i} n_{i}}=\frac{n_{i 0} \exp \left[-\int_{0}^{z} \frac{m_{i} g}{k_{i} n_{i}} d h\right]}{\exp \left[-\int_{0}^{2} \frac{m_{i g}}{k T_{i}} d h\right]}
$$

where all common factors have been removed. Mean ionic mass can now be expressed as;

$$
\left\langle m_{i}\right\rangle=\sum_{i} p_{i} m_{i}=\frac{\sum_{i} n_{i o} m_{i} \exp \left[-\int_{0}^{z m_{i} g} \frac{k_{i}}{k T}\right]}{\sum_{i} n_{i o} \exp \left[-0^{\frac{m_{i} g}{k T_{i}}} d h\right]}
$$

From Eqs. (15) and (16) we see that both $p_{i}$ and $\left\langle m_{i}\right\rangle$ are independent of electron temperature. 
III. OBSERVATIONS OF THE DATA

The stanford station does not have a command capability and thus can obtain data only when the sounder is commanded on by certain nearby command stations. In addition, the sounder is not commanded on especially for the benefit of the stanford receiving station. The stations providing the most advantageous commands are College, Alaska and Grand Forks, Minnesota. The geographic location of these stations tended to concentrate most of the data acquisition to the higher latitudes, i.e. from $48^{\circ}$ dip latitude to $78^{\circ}$ dip latitude.

The height limits are set by other considerations. Consideration of the data is limited to heights greater than $100 \mathrm{~km}$ above the ionization maximum in order to avoid the complicating effects of recombination. Reasonable lower limits were set at $400 \mathrm{~km}$ for both summer and winter results. The upper limit in height is set by practical problems. In the vicinity of the satellite the virtual depth of the signal penetration increases very rapidly with a small increase in sounding frequency. The result is that the ionogram trace has a very steep gradient in the vicinity of the satellite, so steep that it becomes difficult to scale visually. Paul and Wright (1964) have examined this problem and have shown that the ionogram trace approaches an infinite gradient at the satellite, thus making the records difficult to interpret. The scale height profiles we have analysed have shown the effect of this problem, being reasonably consistent up to $850 \mathrm{~km}$ or $900 \mathrm{~km}$, and showing randomly erratic behavior above there, thus determining our upper limit of $900 \mathrm{~km}$.

In general, data acquired during the summer period were more plentiful and of higher quality than the winter data. This was true especially of nighttime passages. There were more passages actually recorded in the summer period than in the winter, and the percentage of nighttime recordings was higher in the summer than in the winter. On many of the ionograms the plasma fre- 
quency at the vehicle could not be determined due to noise or other effects. The net result was that the accuracy of the winter nighttime analysis suffers to some extent from insufficient data.

Figure 1 is a plot of scale height as a function of height at a series of latitudes obtained from a typical nighttime passage. The data are typical for periods from 2300 to 0400 LMT and for both summer and winter records. Each curve, or 4 profile, is associated with a certain latitude and is actually an average of all profiles occurring within \pm 1.5 degrees of that latitude.

Figure 2 represents data from a passage occurring June 10, 1963, from 1130 to 1250 LMT. It is typical, however, of daytime (0800-1700 IMT) data for both summer and winter. only two profiles are plotted because, at least between $450 \mathrm{~km}$ and $850 \mathrm{~km}$, virtually all the data occurred within the narrow region indicated by the dotted lines.

Figures 3 and 4 emphasize the difference in diurnal variation at two different latitudes for summer and winter respectively. Each curve is obtained by averaging the data from 15 or more passages. The daytime curves represent the average of all data recorded from 0800 to 1700 LMT. The nighttime curves represent the average of all data recorded from 2300 to 0400 LMT. It can be seen from the figure that diurnal variation is strongly dependent on latitude.

Figures 5 and 6 illustrate the variations of daytime scale heights with latitude for summer and winter respectively. Each of these plots was obtained from the average of a series (15 to 20) of passages occurring between 0800 and 1700 LMT. The summer profiles are seen to increase slightly with latitude at all altitudes, while the winter profiles are nearly independent of latitude at $500 \mathrm{~km}$ and decrease with latitude at the higher latitudes. 
Figures 7 and 8 illustrate the variations of nighttime scale heights with latitude for summer and winter respectively. These plots were obtained by averaging the data from a series of passages occurring between 2300 and 0400 LMT. The latitudinal variation suggested by Fig. 1 is apparent here also.

Nearly all the Figs. 1-8 show the effects of the presence of an ionization maximum. Most of the profiles tend to increase with decreasing altitude below about $400 \mathrm{~km}$. In the latter part of this paper it is convenient to approximate daytime plasma scale height profiles with a straight line. In this case we will limit our consideration of the data to the region above $500 \mathrm{~km}$.

\section{INTERPRETATION OF RESULTS}

The results of Brace, et al (1963), Evans and Loewenthal (1964) and others suggest that midlatitude nighttime temperature gradients are small. For this situation, a first order approximation to Eq. (4) becomes

$$
\not \approx \frac{\overline{\mathrm{K}}}{\left\langle\mathrm{m}_{\mathbf{i}}\right\rangle}
$$

since in this case

$$
\frac{\partial\left\langle m_{i}>\right.}{\partial h}>>T_{e}^{\prime}+T_{i}^{\prime}
$$

Figure 9 illustrates an isothermal solution to Eq. (24) corresponding to the summer nighttime scale profile occurring at 48 deg, shown in Fig. 3. It can be easily verified that the distribution of Fig. 9 yields a scale height profile which agrees with the experimental profile within $4 \%$ at any height. If we define the transition level by the condition that $\mathrm{P}\left(\mathrm{O}^{+}\right)=50 \%$, 
it may be seen that, in the vicinity of the transition level, i.e., $550 \mathrm{~km}$, that $\left\langle\mathrm{m}_{i}\right\rangle$ does indeed vary quite rapidly, so rapidly in fact that variations in scale height must be due almost entirely to variations in $\left\langle\mathrm{m}_{i}\right\rangle$, as suggested by Eq. (26). In addition, it may be seen that as little as $200 \mathrm{~km}$ below the transition level, $\mathrm{O}^{+}$so completely dominates the mixture, the assumption may be made, with little error, that the only ions present are $\mathrm{O}^{+}$. Finally, consideration of experimental values of scale height and reasonable values of temperatures indicates that the transition must indeed be from $\mathrm{O}^{+}$to lighter ions.

It is easily shown that a similar analysis may be performed on the winter nighttime scale height profile at 48 deg as shown in Fig. 4, yielding similar temperature and distribution results, with a transition level at about $500 \mathrm{~km}$.

\section{A. VARIATIONS OF THE TRANSITION LEVEL}

We have seen that the deflection of an experimental scale height profile identifies a transition from $\mathrm{O}^{+}$to $\mathrm{H}_{e}{ }^{+}$and/or $\mathrm{H}^{+}$ions. We have estimated that the height of this transition can be determined to within an accuracy of, perhaps, $\pm 25 \mathrm{~km}$. It is now convenient to attempt to describe this transition level in a different manner than previously used.

Since a transition is defined by the condition $\mathrm{P}\left(\mathrm{O}^{+}\right)=50 \%$, then at the transition level for any arbitrary concentrations of $\mathrm{H}_{\mathrm{e}}^{+}$and $\mathrm{H}^{+},\left\langle\mathrm{m}_{i}\right\rangle$ must lie between $8.5 \mathrm{amu}$ and $10 \mathrm{amu}$. If temperature gradients are not too large we can say that transition corresponds approximately to the conditions;

$$
\begin{gathered}
H\left(h_{T}\right) \approx 1.6 \nLeftarrow\left(h_{m i n}\right) \\
h_{T} \approx 200 \mathrm{~km}+h_{\min }
\end{gathered}
$$




$$
\frac{d}{d h} \not\left(h_{\text {min }}\right) \ll \frac{d}{d h} \not \psi\left(h_{T}\right)
$$

where $h_{T}$ is the transition level and $h_{\min }$ is a height below which \& variations are small. Obviously the application of conditions (18), (19), and (20) requires some judgement but it is easily verified that a plasma scale height profile in the vicinity of a transition does satisfy these conditions and that conversely, only a sharply deflecting plasma scale height profile can satisfy these conditions. Finally, it can be argued that such a deflection can arise only from an ion transition or from unacceptably large local temperature gradients. It can thus be reasoned that the successful application of conditions (18), (19) and (20) to any plasma scale height profile does indeed establish and locate a transition.

When these conditions were applied to each plasma scale height profile for each satellite passage, and the resulting transition height for each profile plotted against the latitude at which it occurred, it was seen that in all cases the resulting plot showed a monotonic increase with latitude. In Fig. 10 we have shown the results of drawing a smooth curve through values of transition level which were obtained at three degree latitude intervals by averaging the results of a series of summer passages and a series of winter passages. These curves have also been plotted as dashed lines in Figs. 7 and 8.

There are two other important conclusions we can draw from the curves in Fig. 10. First, as pointed out earlier, the relative ion concentration is independent of electron temperature. The curves indicate therefore, that ion temperature increases with increasing latitude. Second, at depths as small as $200 \mathrm{~km}$ below the transition level, $\mathrm{O}^{+}$concentration completely dominates, so that at higher latitudes variations in scale height must be due almost entirely to temperature effects. 
Using the same method we can study the variation of transition level with time. Figure 11 shows a plot of transition level as a function of time for all profiles obtained at $48 \pm 1.5$ deg dip latitude. The trend of variation of the transition level suggested by Fig. 11 is that the level rises rather quickly at dawn, descends quickly at sunset, and remains fairly constant through most of the night. One should be cautious about attempting to draw quantitative conclusions from the curve since at sunrise and sunset, neither time derivatives nor transport velocities are likely to be negligible, but the evidence that the transition level is higher by day than by night is quite strong. If we assume that the daytime transition level is at least as high as $1000 \mathrm{~km}$, then the approximation can be made that the ion composition in the region below $800 \mathrm{~km}$ is only $\mathrm{O}^{+}$, and we can interpret changes in daytime scale height entirely in terms of electron temperature and ion temperature.

\section{B. THE $\mathrm{O}^{+}$APPROXIMATION}

Within the $\mathrm{O}^{+}$region, i.e., more than $200 \mathrm{~km}$ below the transition level, we can make the approximation that mean ionic mass is constant at a value of 16 amu. scale height variations can thus be interpreted entirely in terms of temperature variations.

As a matter of convenience, then, we introduce the definition

$$
H=\frac{k\left(T_{e}+T_{i}\right)}{2 m\left(O^{+}\right) g}
$$

so that, upon neglecting the small variation in gravity, we can express Eq. (4) as

$$
H=\frac{\mathrm{H}}{\mathrm{H}^{\prime}+\frac{1}{2}}
$$


It may be seen from Figs. 3, 4, 5, and 6 that the daytime and high latitude nighttime data are quite linear with height, at least above $500 \mathrm{~km}$. On this basis we approximate any such profile with a straight line form; i.e.

$$
\notin=\mathrm{a}+\mathrm{bz}
$$

where $a$ and $b$ are obtained from the data and $z=0$ at $500 \mathrm{~km}$. For example, the Day (48 deg) profile of Fig. 3 is given approximately by $\forall=185+0.5 \mathrm{z}$.

Equation (22) can now be expressed as

$$
H^{\prime}=\frac{H}{a+b z}-\frac{1}{2}
$$

for which a solution is

$$
H=c(z+a / b) \frac{1}{b}+\frac{b / 2}{1-b}(z+a / b)
$$

where $C$ is an arbitrary constant.

To determine values for $T_{e}$ and $T_{i}$ from Eq. (25), we can appeal to the theoretical work of Hanson (1963) and Geisler and Bowhill (1965) and the experimental results of Evans and Loewenthal (1964). Following the results of these workers we assume that $T_{e}$ is isothermal and that $T_{i}$ increases with height, approaching $T_{e}$ as an upper limit such that $T_{i}^{\prime}(800)=0$ and $\mathrm{T}_{\mathrm{i}}(800)=\mathrm{T}_{\mathrm{e}}$.

These conditions provide the boundaries needed to solve Eqs. (2I) and (25) for values of $T_{e}$ and $T_{i}$. For the scale heights shown in Figs. 5 through 8, the corresponding solutions for $\mathrm{T}_{e}$ and $T_{i}$ are shown in Figs. 12 through 15 respectively.

Estimates of midlatitude nighttime temperatures were obtained on the assumption that electron and ion temperatures were 
equal and isothermal. Estimates of high latitude nighttime temperatures are here obtained on the assumption that mean ionic mass is independent of height. In the latitude region between $48 \mathrm{deg}$ and $63 \mathrm{deg}$, however, neither assumption is likely to be appropriate. For this reason the solutions obtained in the two regions have been connected with smooth dashed lines as shown in Figs. 14 and 15, where the temperatures at 48 deg are consistent with the 48 deg nighttime profiles of Figs. 3 and 4.

A comparison of Figs. 14 and 15 shows that for both summer and winter nighttime conditions, temperatures appear to increase with increasing latitude, reaching a maximum at between 65 deg and 70 deg latitude, although summer temperatures appear to be a bit higher. The apparent trough in the winter temperatures may not be genuine. The winter data in this region was rather sparse, and it is entirely possible that the indication of another temperature increase north of 72 deg might be caused by an increasing ratio of lighter ions to $\mathrm{O}^{+}$ions in this region.

A downward flux of energetic particles from sources such as the solar wind or the Van Allen Belts might account for this, although it seems that particles depositing appreciable energy at these altitudes would have to be of fairly low energy. Thus far, the measurement of energetic particle fluxes appears to have been limited to particles with energies greater than about $40 \mathrm{kev}$.

From purely geometric considerations, the region above about 65 deg latitude is sunlit nearly all night during the summer period. The summer night high latitude temperatures are thus likely to be the result of both solar flux and whatever heating mechanism is producing the winter conditions. Such an assumption would explain both the higher temperatures during the summer, and also the fact that the temperature peaks occur at about 5 deg higher latitude in the summer than in the winter. 


\section{CONCLUSIONS}

Under the assumption that the topside ionosphere is in a state of diffusive equilibrium, the measured parameter scale height bears a simple relationship to the electron temperature, ion temperature and relative ion concentration.

A midlatitude nighttime transition from $\mathrm{O}^{+}$ions to lighter (i.e., $\mathrm{H}_{e^{+}}, \mathrm{H}^{+}$) ions is shown to exist at about $550 \mathrm{~km}$ in the summer and $500 \mathrm{~km}$ in the winter. The accuracy of this determination is estimated to be $\pm 25 \mathrm{~km}$. The transition is shown to be characteristically narrow, such that, as little as $200 \mathrm{~km}$ below the transition, it is a reasonable approximation that the only ions present are $\mathrm{O}^{+}$. Using this approximation, the daytime and the high latitude nighttime scale height variations are interpreted in terms of temperature variations.

Daytime temperatures for both summer and winter are observed to vary only slightly with latitude, while the more pronounced height variations are seen to agree reasonably well with the theoretical results of Hanson (1963) and Geisler and Bowhill (1965).

Nighttime temperatures for both summer and winter show a much greater latitudinal effect, with both a fairly sharp peak and a pronounced upward gradient at about 65-70 deg dip latitude, suggesting a significant source of heat energy in this region.

\section{ACKNOWLEDGMENTS}

The advice and counsel of Professor $O$. K. Garriott, under whose direction this work was performed, is greatly appreciated. Also appreciated are many helpful suggestions from Dr. Henry Rishbeth. Financial support has come from NASA Grants NsG 30-60 and NGR 05-020-089 to Stanford University. 


\section{BIBLIOGRAPHY}

1. Barrington, R. E., J. S. Belrose, and G. L. Nelms, "Ion Composition and Temperatures at $1000 \mathrm{~km}$ as Deduced from Simultaneous Observations of a VLF Plasma Resonance and Topside Sounding Data in the Alouette I Satellite," I. Geophys. Res., 70, 1965, p. 1647.

2. Bowen, P. J., et al, "Ion Composition of the Upper F Region," Proc. Roy. Soc., A281, 1964, p. 504.

3. Brace, L. H., N. W. Spencer, and G. R. Carignan, "Ionosphere Electron Temperature Measurements and their Implications," J. Geophys. Res., 68, 1963, p. 5397 .

4. Evans, J. V., and M. Loewenthal, "Ionospheric Backscatter Observations," Plan, Space Sci., 12, 1964, p. 915.

5. Geisler, J. E., and S. A. Bowhill, "An Investigation of Ionosphere-Protonosphere Coupling," Aeronomy Report No. 5 Dept. of Electrical Engineering, University of Illinois January, 1965.

6. Hanson, W。 B., "Electron Temperatures in the Upper Atmosphere," Space Research III, John Wiley \& Sons, Inc., New York, May 1962, p. 282 .

7. Johnson, C. Y., E. B. Meadows, and J': C. Holmes, "Ion Composition of the Arctic Ionosphere," J. Geophys.Res., 63,1958, p. 443 .

8. King, J. W., et al, "Preliminary Investigation of the Structure of the Upper Ionosphere as observed by the Topside Sounder satelilte, Alouette," Proc. Roy. Soc., A281, 1964, p. 464 .

9. Nicolet, M., "Helium, an Important Constituent in the Lower Exosphere," J. Geophys, Res., 66, 1961, p. 2263.

10. Paul, A. K., and J. W. Wright, "Electron Density Profile Analysis of Topside Sounder Ionograms," J.Geophys.Res., 69, 1964, p. 1431 .

11. Taylor, H. A., L. H. Brace, H. C. Brinton and C. R. Smith, "Dixect Measurement of Helium and Hydrogen Ion Concentration and Total Ion Density to an Altitude of $940 \mathrm{~km}$, " J. Geophys. Res., 68, 5339, 1963 . 
12. Thomas, J. O., B. R. Briggs, L. Colin, M. J. Rycroft, and M: Covert, "Ionosphere Topside Sounder Studies I - The Reduction of Alouette I Ionograms to Electron Density Profiles" NASA TN D-2882, 1965.

13. Thomas, J. O., M. J. Rycroft, M. Covert, B. R. Briggs, and L. Colin, "Ionosphere Topside sounder Studies II - The Calculation of the Electron Density and the Magnetic Field Parameters at the Alouette I Orbit," NASA TN D-2921, 1965.

14. Thomas, J. O., M. Rycroft, and L. Colin, "Tables of Electron Densities and Scale Heights in the Topside Ionosphere," Vol. I, Nos. 1-6, Alouette Observations at Stanford University, NASA special Report, 1965 (in press).

15. Thomas, J. O., and A. Y. Sader, "Electron Density at the Alouette Orbit," J. Geophys. Res., 69, 1964, p. 4561. 
FIGURE CAFTIONS

Fig. 1. Experimental results from a typical nighttime passage showing scale height [A(h)] profiles at a series of dip latitudes, and illustrating the variation of the profiles with latitude. Data obtained from Passage No. 3346, 0200-0330 LMT, June 1, 1963.

Fig. 2. Experimental results from a typical daytime passage showing scale height [H(h)] profiles at two widely separated dip latitudes, and illustrating the consistency of the daytime results. All the data for the entire passage, if plotted, would lie..between the dotted lines. Data obtained from Passage No.3474, 1140-1250 LMT, June 10, 1963.

Fig. 3. Comparison of daytime and nighttime scale height $[\not(h)]$ profiles at two widely spaced dip latitudes showing the contrast at the lower latitudes and the similarity at the high latitudes. Each curve represents the average of data from at least 15 passages occurring May - July 1963.

Fig. 4. Comparison of daytime and nighttime scale height $\not(h)$ profiles at two widely spaced dip latitudes showing the contrast at the lower latitudes and the similarity at the high latitudes. Each curve represents the average of data from at least 15 passages occurring November 1963 - January 1964 .

Fig. 5. Summer daytime scale height as a function of dip latitude at several altitudes. Each curve represents the average of data obtained from at least 15 passages occurring between 0800 and 1700 IMT. May - July 1963.

Fig. 6. Winter daytime scale height as a function of dip latitude at several altitudes. Each curve represents the average of data obtained from at least 15 passages occurring between 0800 and 1700 LMT. November 1963 January 1964 .

Fig. 7. Summer nighttime scale height as a function of dip latitude at a series of altitudes. Each curve represents the average of data obtained from at least 15 passages occurring between 2300 and 0400 LMT. The dotted line represents the transition level $\left(\mathrm{O}^{+}-\mathrm{H}_{e}^{+}, \mathrm{H}^{+}\right)$. May July 1963 . 
Fig. 8. Winter nighttime scale height as a function of dip latitude at a series of altitudes. Each curve represents the average of data obtained from at least 15 passages occurring between 2300 and 0400 LMT. The dotted line represents the transition level $\mathrm{O}^{+}{ }^{+} \mathrm{H}_{e}{ }^{+}$, $\mathrm{H}^{+}$). November 1963 - January 1964 .

Fig. 9. Percentage compositions of $\mathrm{O}^{+}, \mathrm{H}^{+}$, and $\mathrm{H}^{+}$as functions of height for an ionosphere in which $\mathrm{T}_{e}=\mathrm{T}_{i}=928^{\circ} \mathrm{K}$ and percentage concentrations at $550 \mathrm{~km}^{1}$ are specified as $\%\left(\mathrm{O}^{+}\right)=50 \%, \%\left(\mathrm{H}^{+}\right)=32 \%$, $\%\left(\mathrm{H}^{+}\right)=18 \%$.

Fig. 10. Nighttime transition level as a function of latitude for summer (May - July 1963) and winter (November 1963 January 1964). Transition level is defined as the height at which the percentage concentration of $0^{+}$ is $50 \%$. Each curve is obtained from the average data from at least 15 passages occurring between 2300 LMT and 0400 LMT:

Fig. 11. Transition level at 48 deg dip latitude as a function of time for summer (May - July 1963) and winter (November 1963 - January 1964). Transition level is defined as the height at which the percentage concentration of $0^{+}$is $50 \%$. The dotted portions of the curves represent incomplete data.

Fig. 12. Electron and ion temperatures as functions of dip latitude for daytime summer (May - July 1963). Electron temperature is assumed everywhere independent of height and is represented by the $800 \mathrm{~km}$ curve. Ion temperatures are shown at four heights and $\mathrm{T}_{\mathbf{e}}=\mathrm{T}_{\mathrm{i}}$ at $800 \mathrm{~km}$.

Fig. 13. Electron and ion temperatures as functions of dip latitude for daytime winter (November 1963 - January 1964). Electron temperature is assumed everywhere independent of height and is represented by the 800 $\mathrm{km}$ curve; ion temperatures are shown at four heights and $T_{e}=T_{i}$ at $800 \mathrm{~km}$ 。

Fig. 14. Electron and ion temperatures as functions of dip latitude for nighttime summer (May - July 1963). Electron temperature is assumed everywhere independent of height and is represented by the $800 \mathrm{~km}$ curve. Ion temperatures are shown at four heights and $\mathrm{T}_{\mathrm{e}}=\mathrm{T}_{\mathrm{i}}$ at $800 \mathrm{~km}$. Below $63 \mathrm{deg}$ dip latitude, temperatures are represented approximately by the dotted extensions to the curves. 
Fig. 15. Electron and ion temperatures as functions of dip latitude for nighttime winter (November 1963 - January 1964). Electron temperature is assumed everywhere independent of height and is represented by the $800 \mathrm{~km}$ curve. Ion temperatures are shown at three heights and $T_{e}=T_{i}$ at $800 \mathrm{~km}$. Below the $63 \mathrm{deg}$ dip latitude, Eemperatures are represented approximately by the dotted extensions to the curves. 


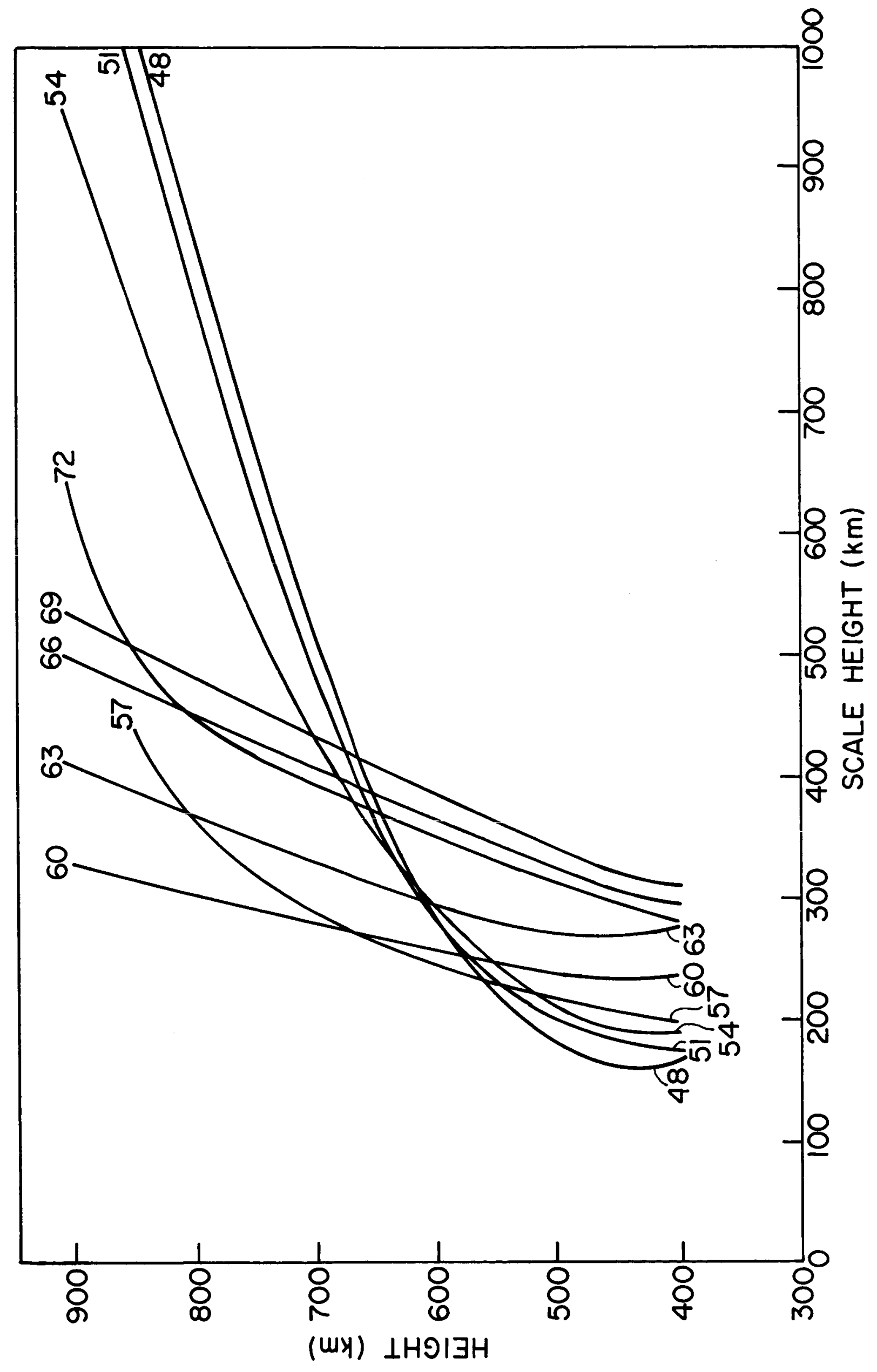




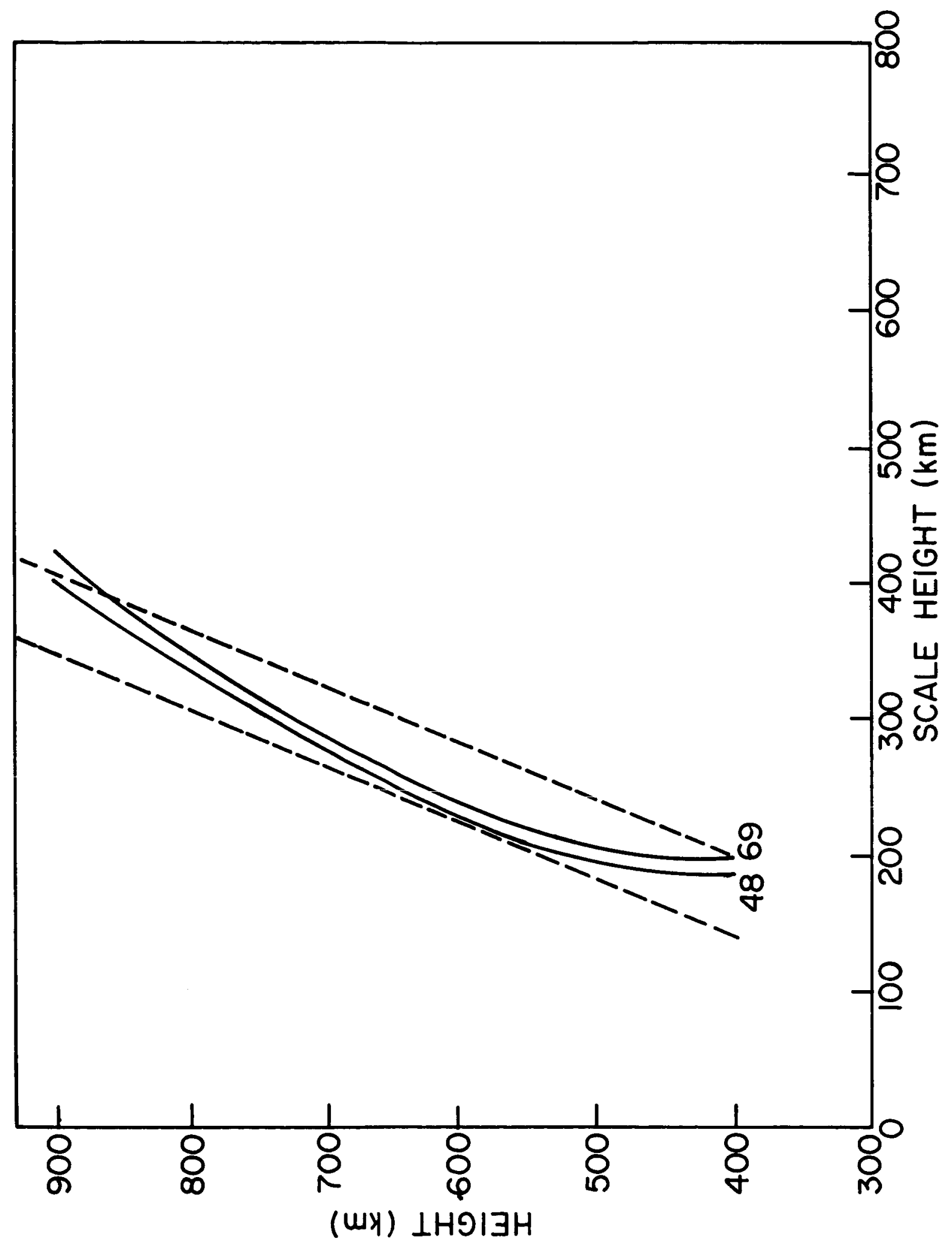




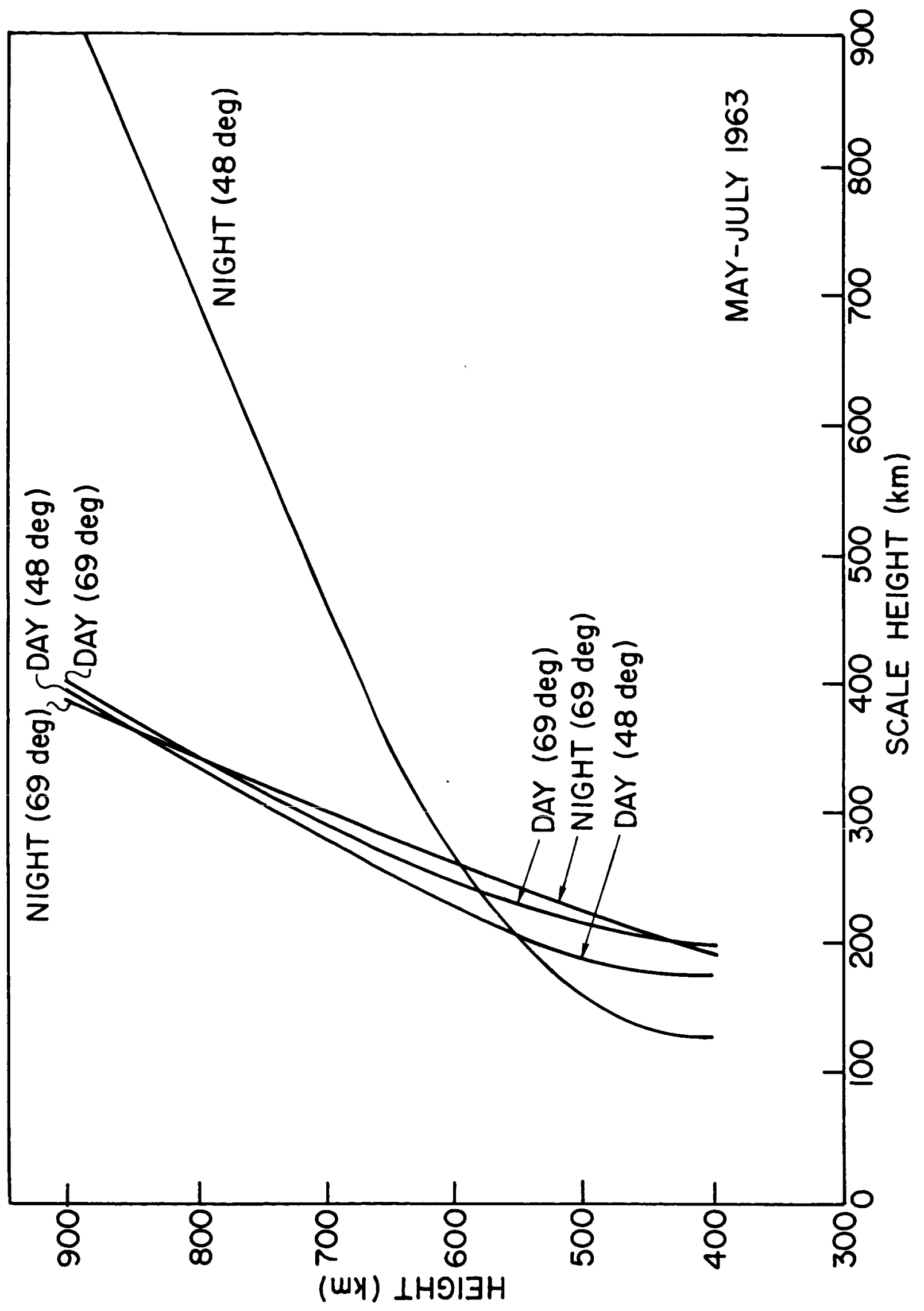




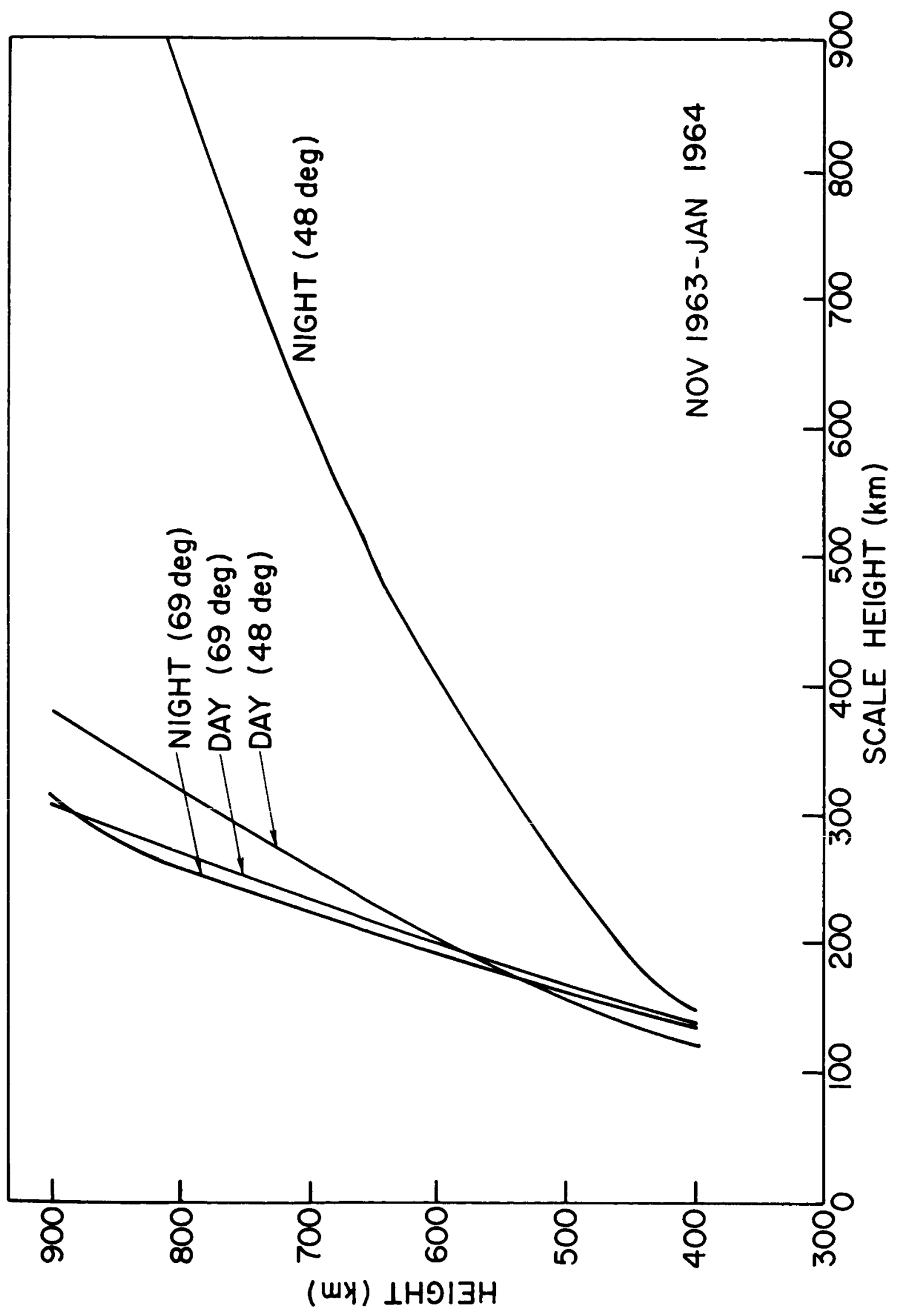




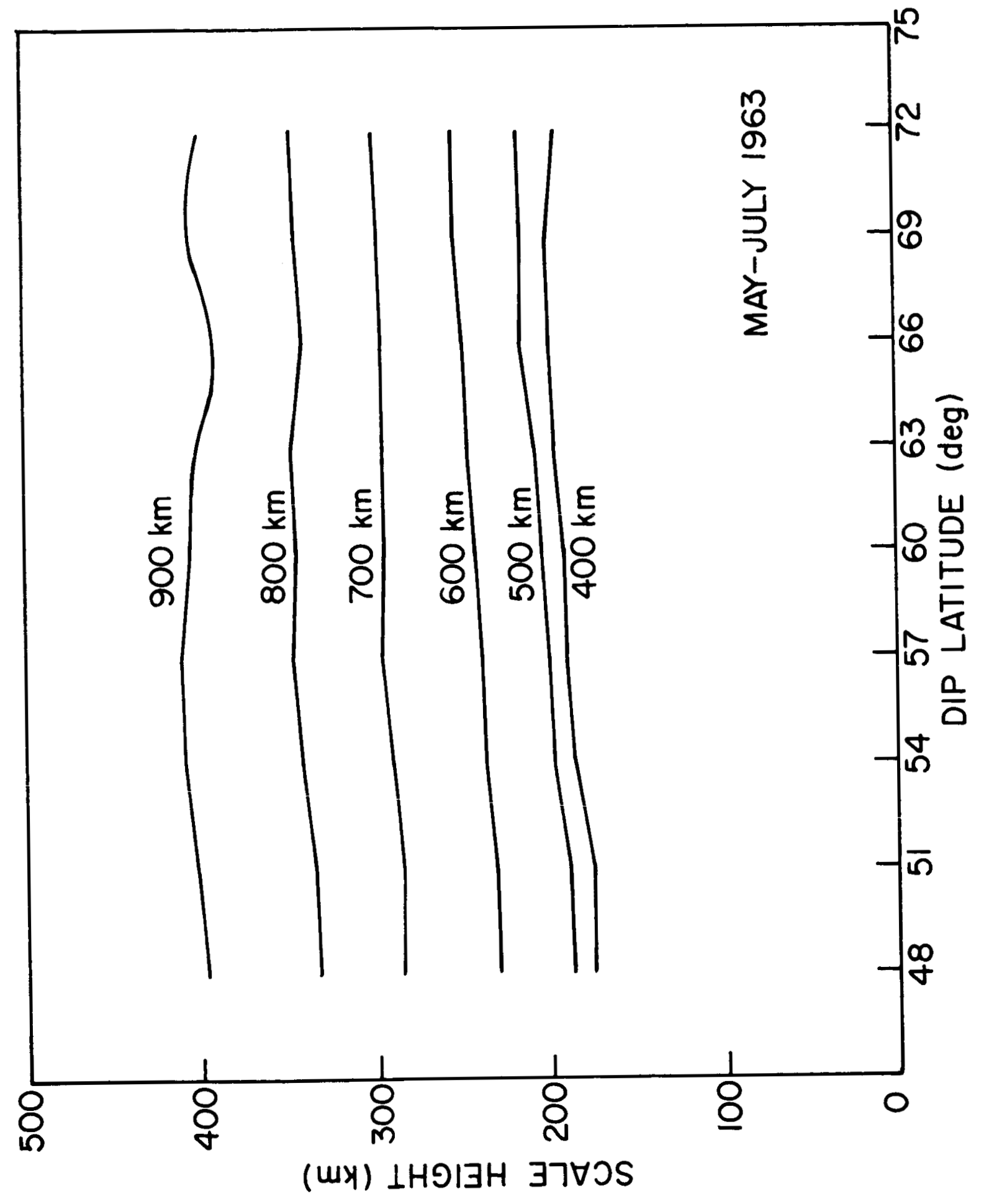




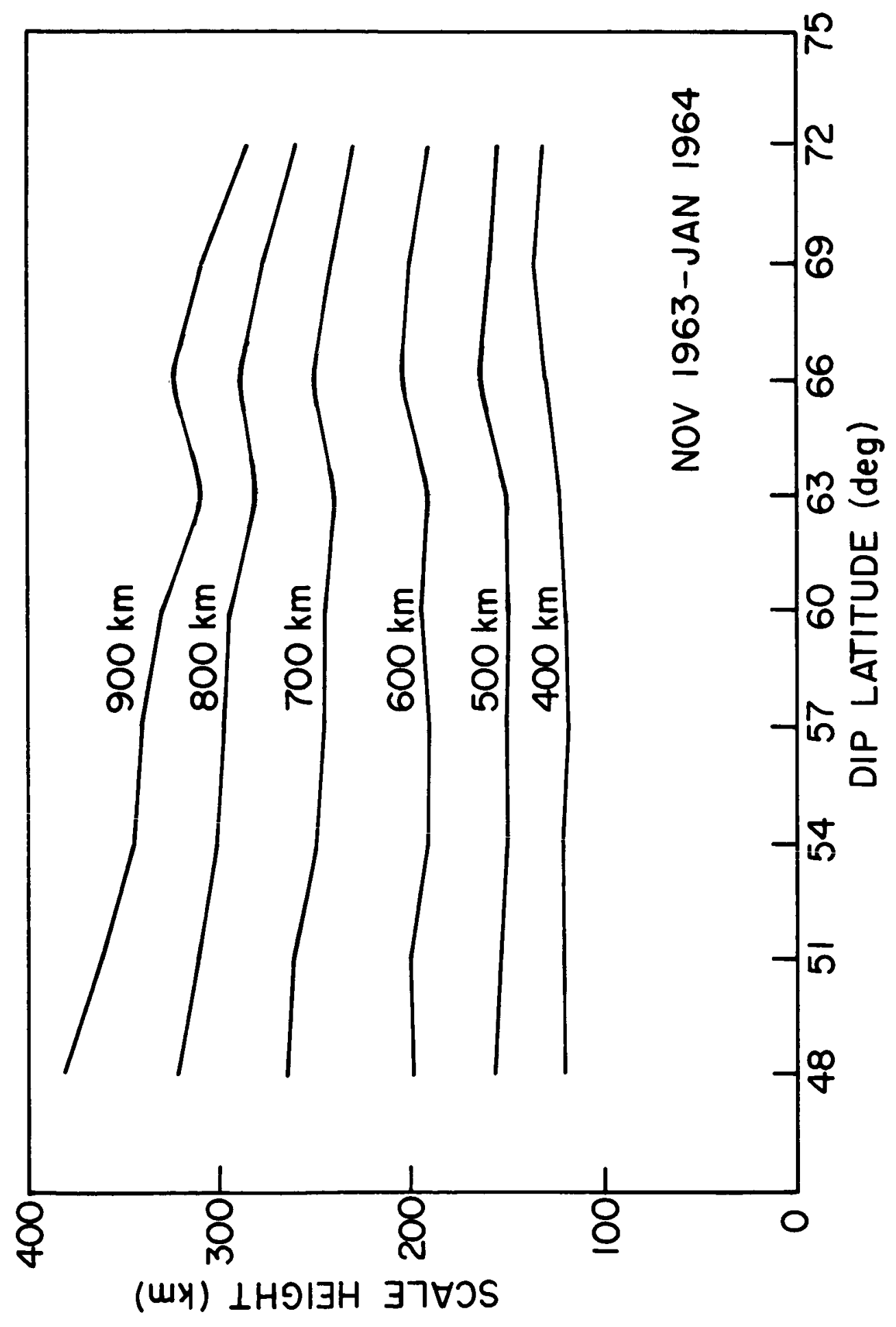




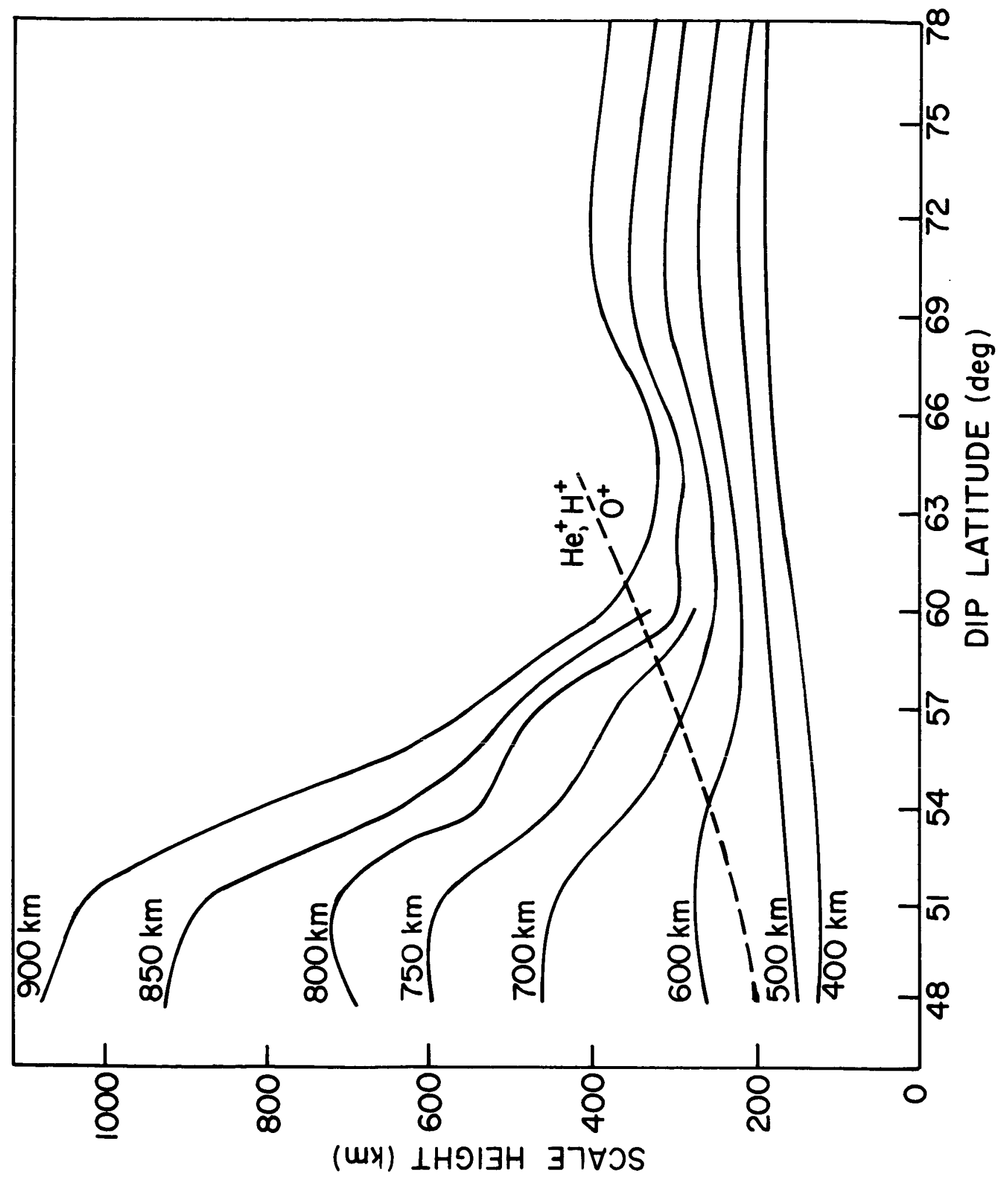




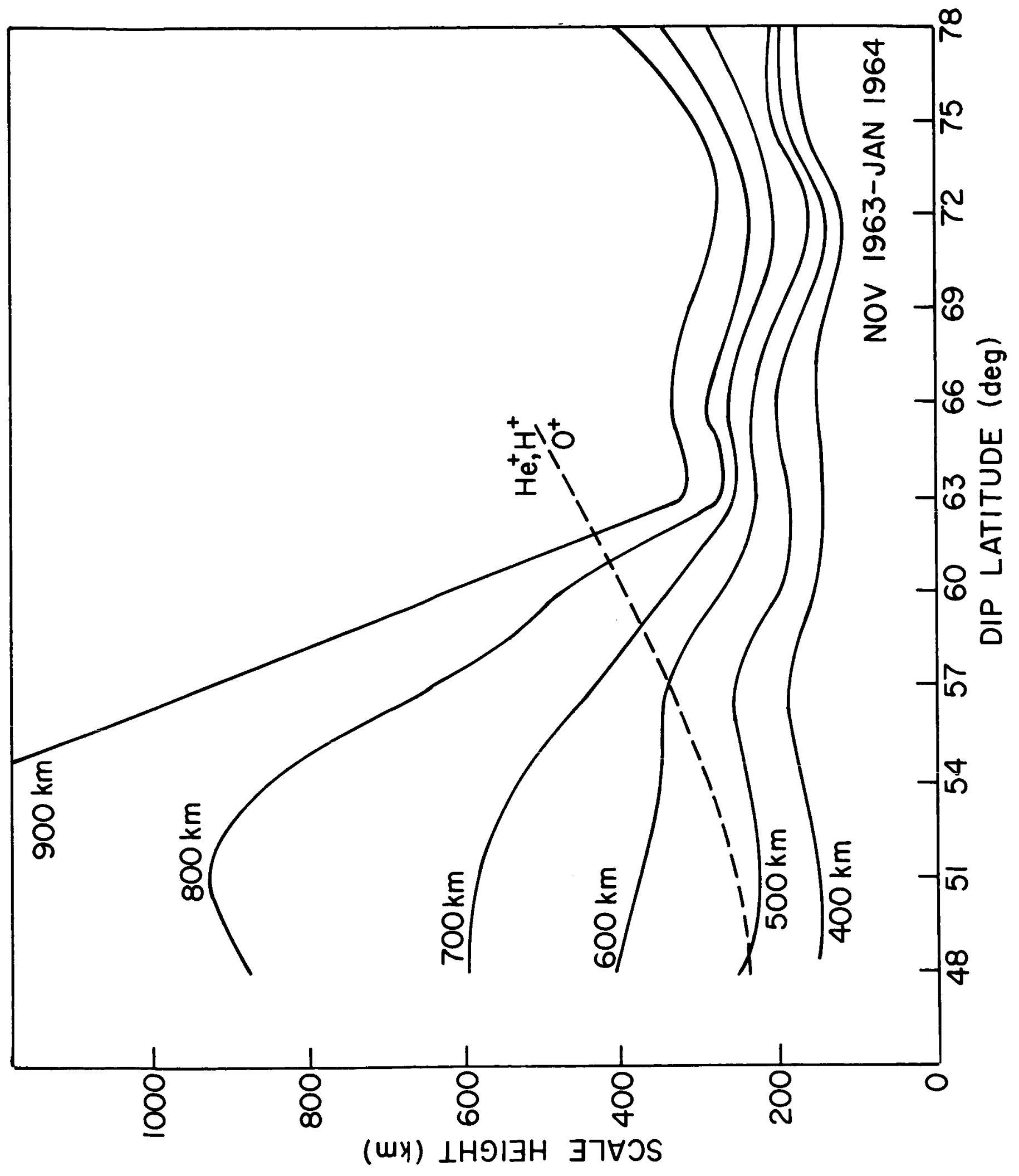




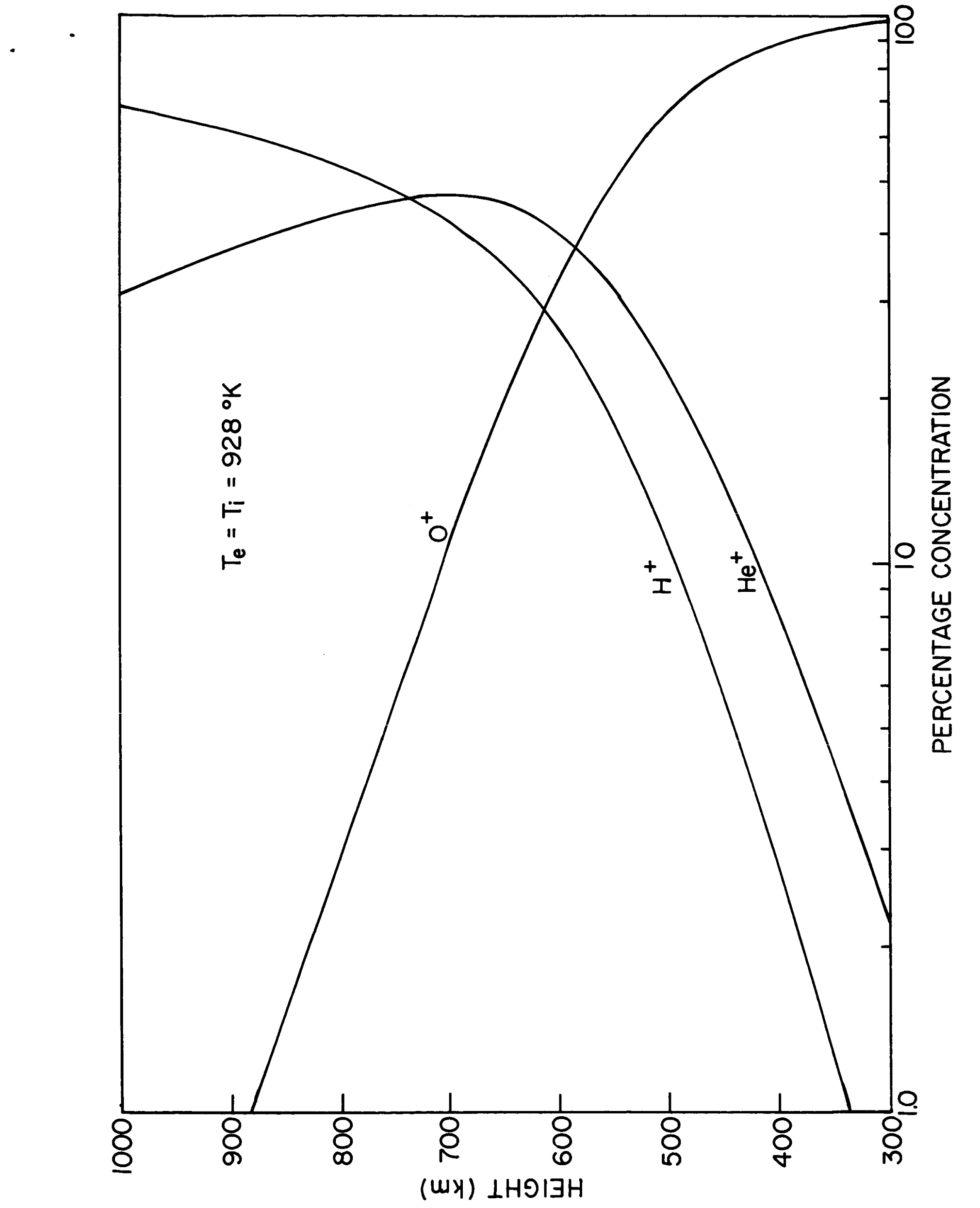




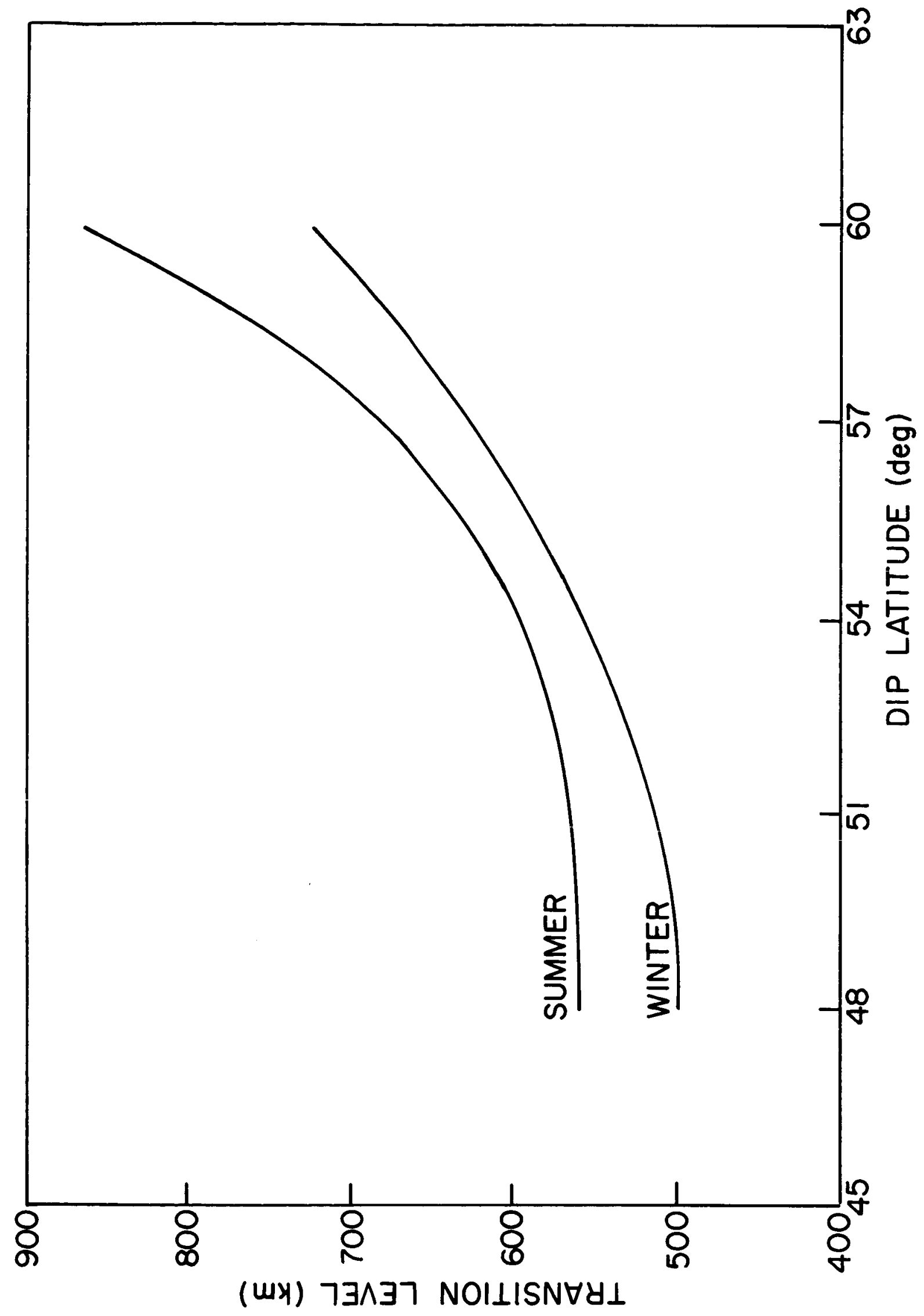




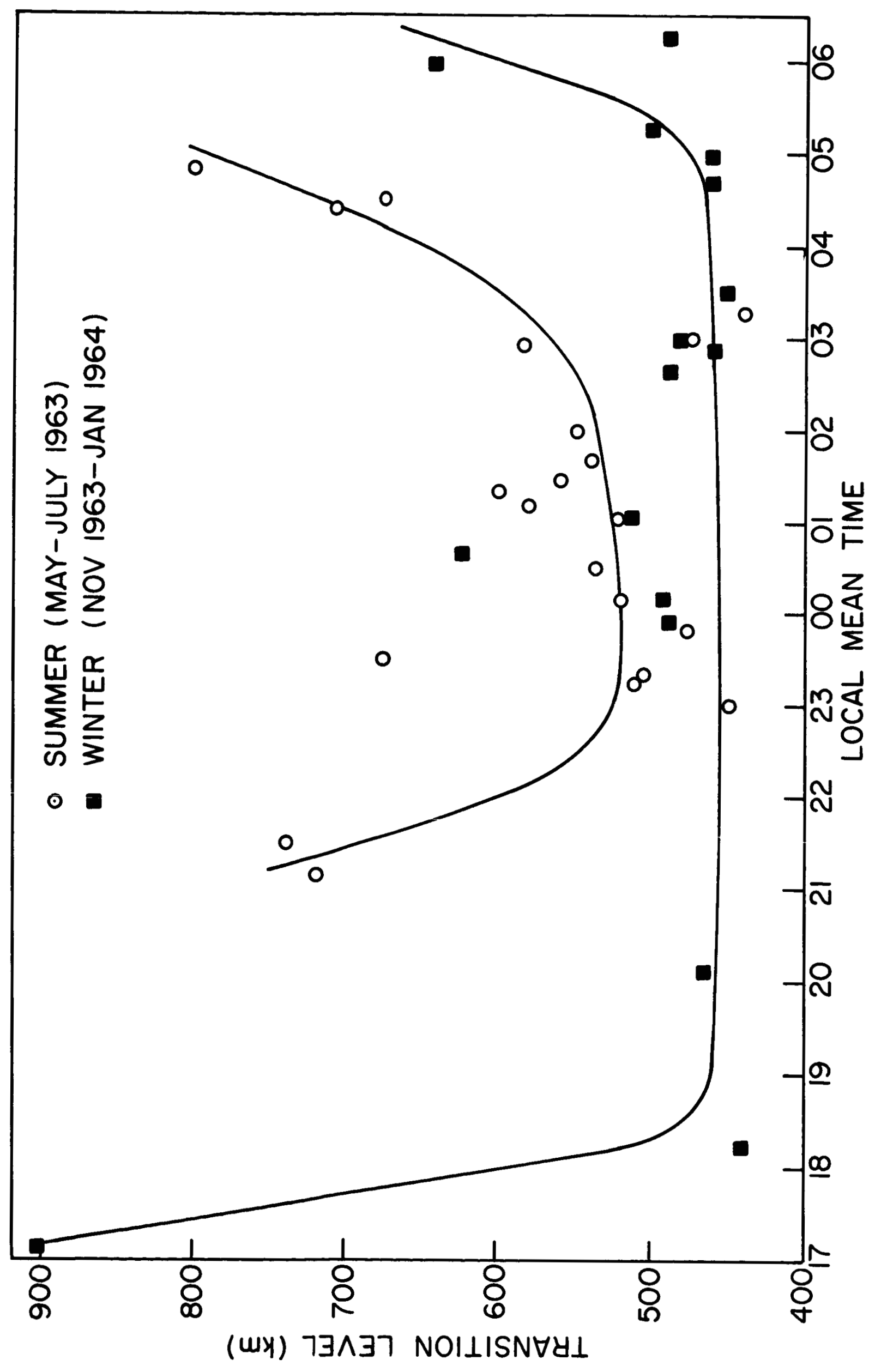




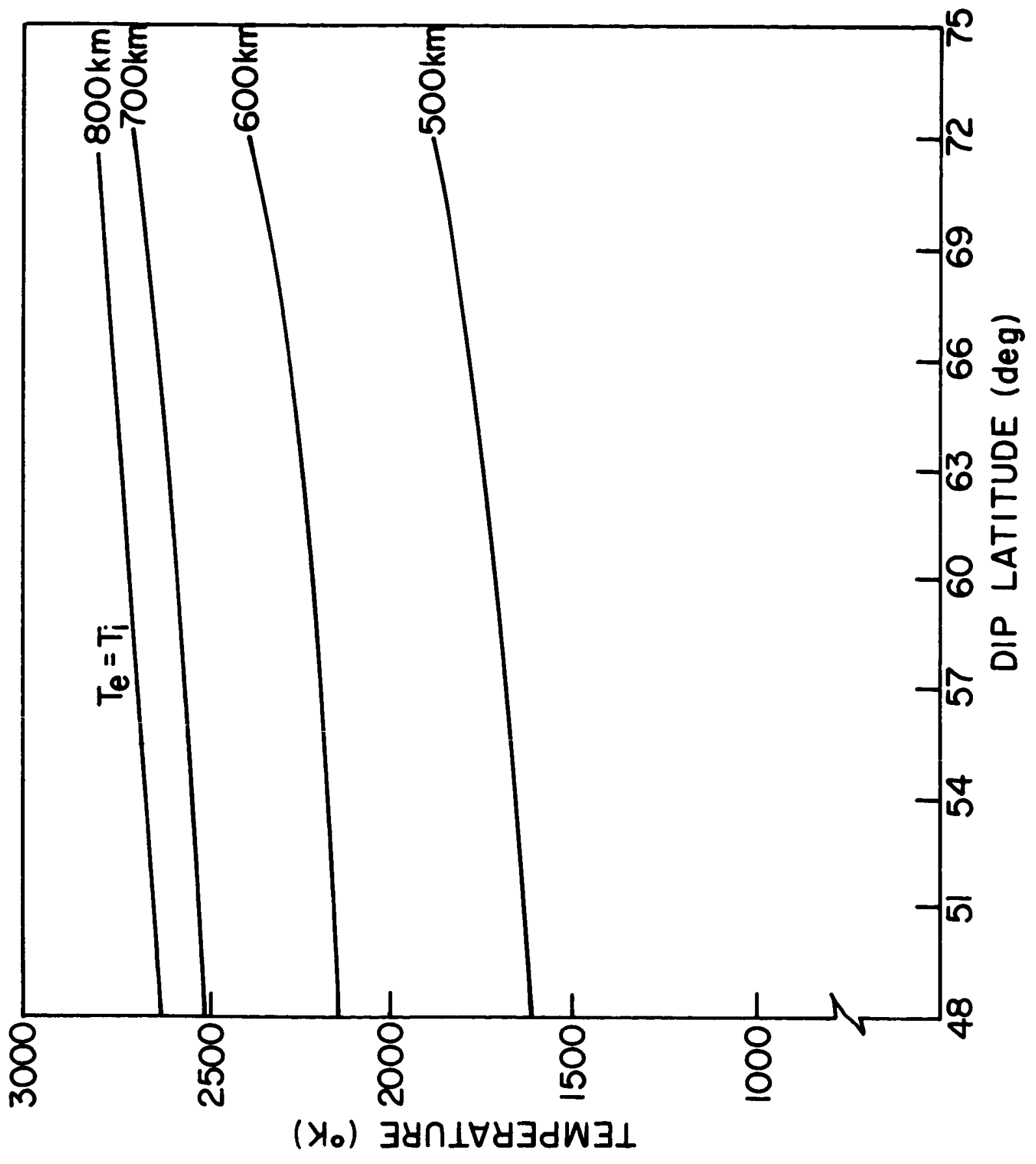




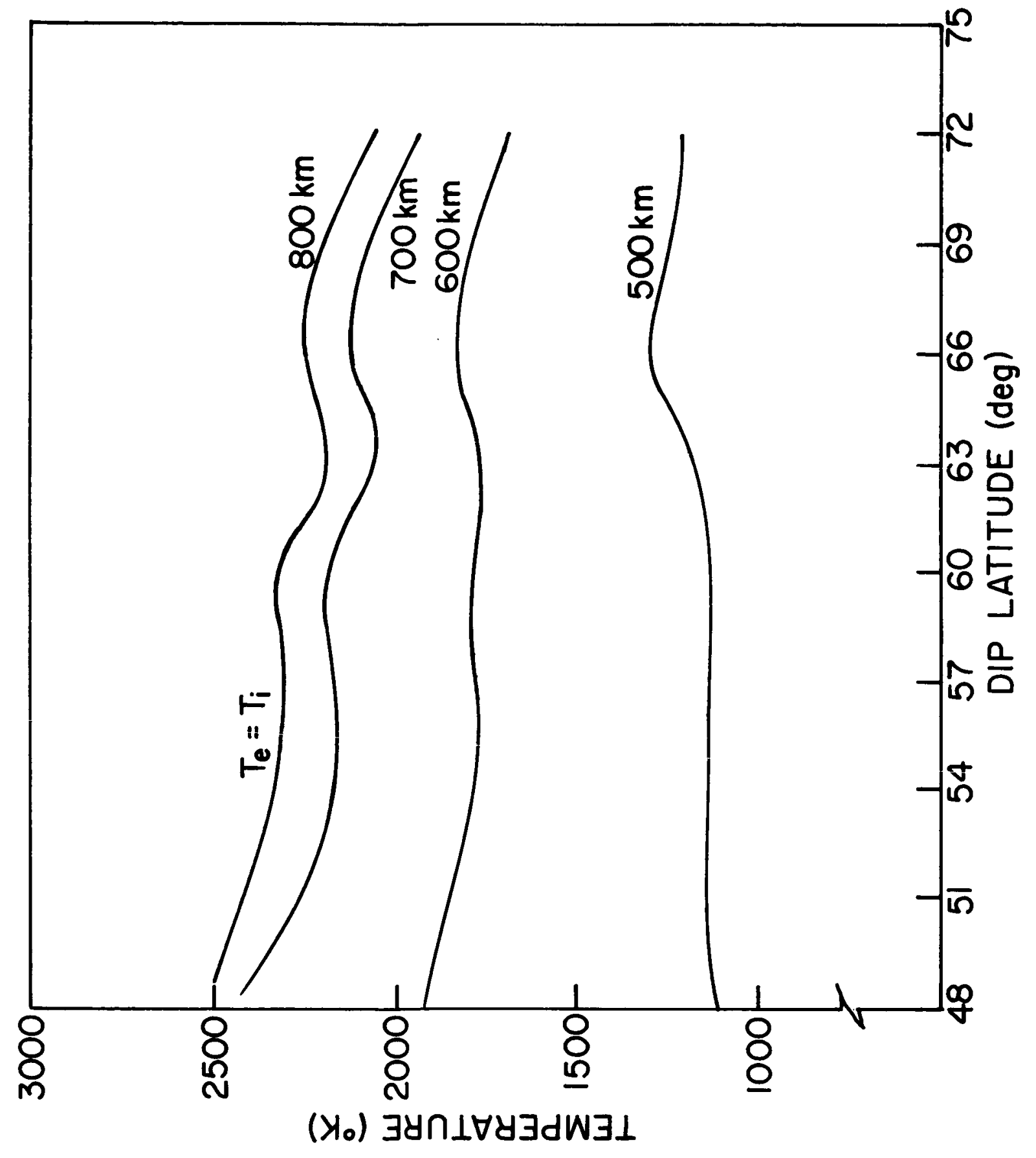




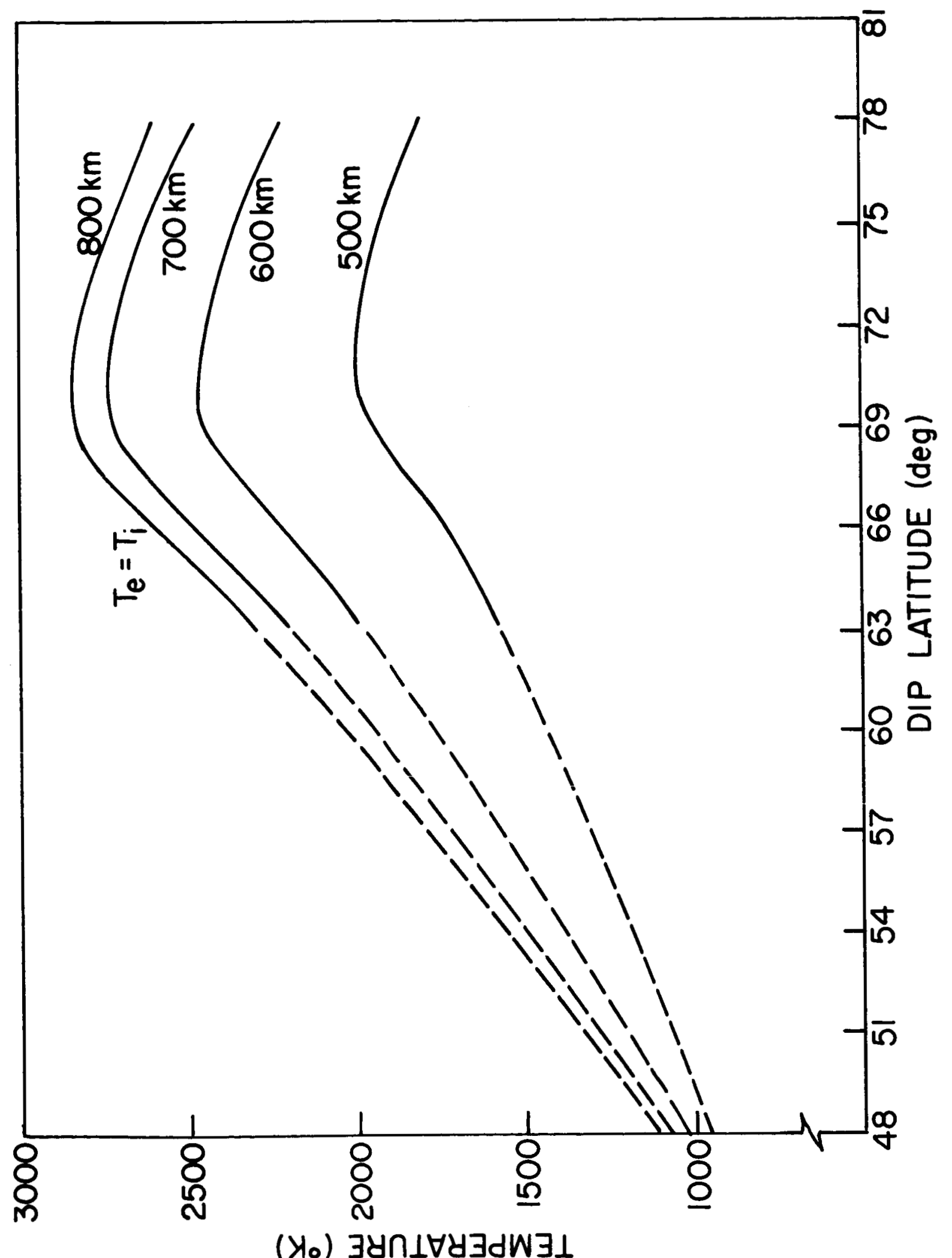




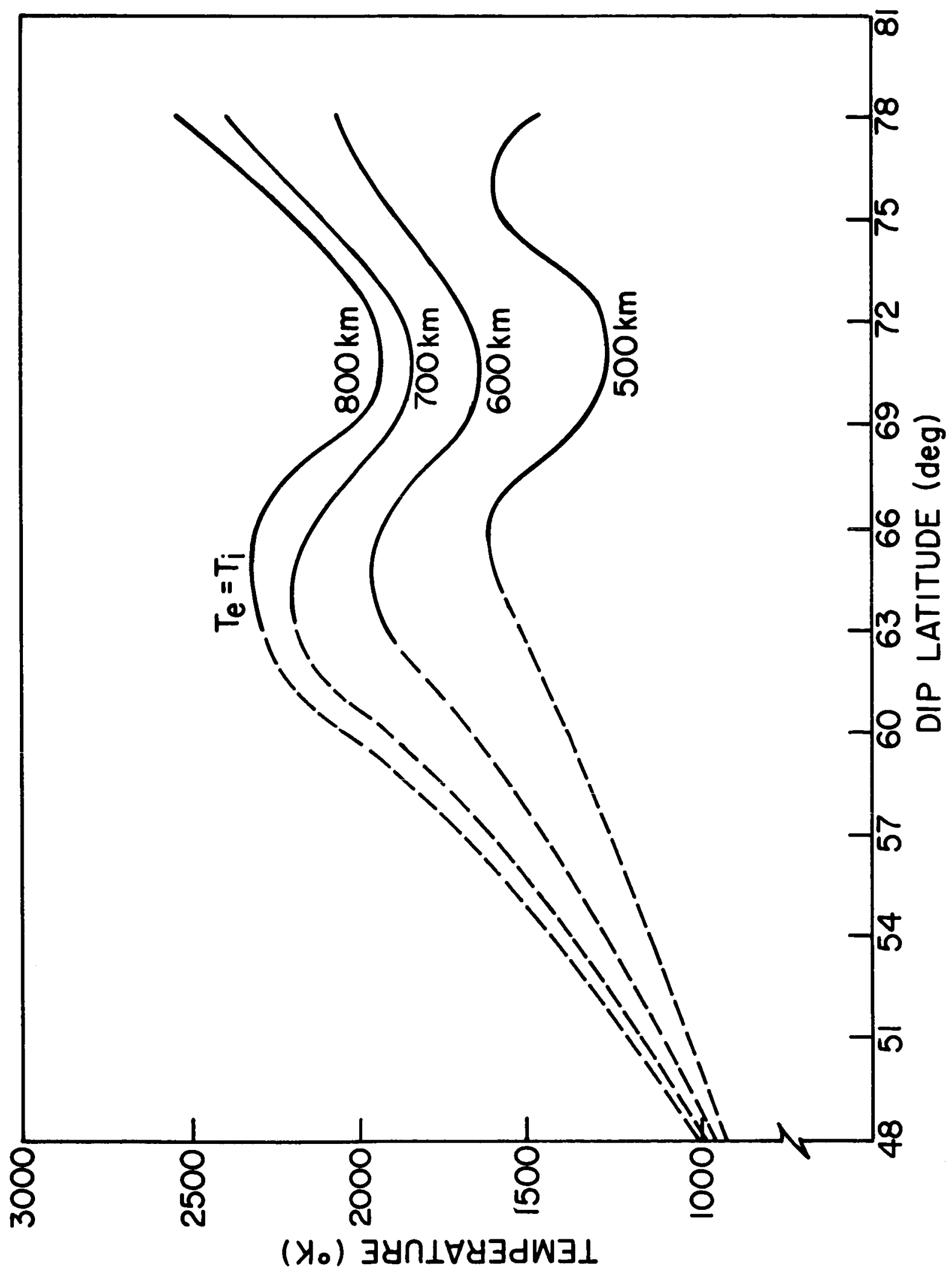

